\title{
Increased nitrotyrosine in exhaled breath condensate in cystic fibrosis
}

\author{
B. Balint*, S.A. Kharitonov*, T. Hanazawa*, L.E. Donnelly*, P.L. Shah\#, M.E. Hodson*, \\ P.J. Barnes*
}

\begin{abstract}
Increased nitrotyrosine in exhaled breath condensate in cystic fibrosis. B. Balint, S.A. Kharitonov, T. Hanazawa, L.E. Donnelly, P.L. Shah, M.E. Hodson, P.J. Barnes. (C) ERS Journals Ltd 2001.

ABSTRACT: Exhaled nitric oxide (ENO), a marker of inflammation in airway diseases is decreased in cystic fibrosis (CF) patients, perhaps because nitric oxide (NO) is metabolized to oxidative end-products. A stable product, 3-nitrotyrosine, may indicate local formation of reactive nitrogen species.

Whether NO metabolites in exhaled breath condensate may be increased in CF patients was investigated. The fractional concentration of ENO ( $F$ eno), nitrotyrosine and oxides of nitrogen in exhaled breath condensate from 36 stable $C F$ patients were compared to 14 normal subjects using an enzyme immunoassay and fluorescence assay.

Nitrotyrosine levels in breath condensate were increased significantly in stable $\mathbf{C F}$ patients, compared with normal subjects $\left(25.3 \pm 1.5\right.$ versus $6.3 \pm 0.8 \mathrm{ng} \cdot \mathrm{mL}^{-1}$, $\mathbf{p}<\mathbf{0 . 0 0 0 1 )}$. There was an inverse correlation between the levels of nitrotyrosine and the severity of lung disease. $F$ eno levels were significantly lower in $\mathrm{CF}$ patients than in normal subjects $(4.4 \pm 0.3$ versus $5.6 \pm 0.4$ (parts per billion), $\mathrm{p}<0.05$ ). No correlation was found between nitrotyrosine and $F$ eno levels in $C F$. There was no significant difference in the levels of nitrite and nitrate between $C F$ patients and normals.

The elevation in nitrotyrosine may reflect increased formation of reactive nitrogen species such as peroxynitrite or direct nitration by granulocyte peroxidases, indicating increased oxidative stress in airways of cystic fibrosis patients.
\end{abstract} Eur Respir J 2001; 17: 1201-1207.

\begin{abstract}
*Dept of Thoracic Medicine and ${ }^{\#}$ Dept of Cystic Fibrosis, Imperial College School of Medicine at the National Heart and Lung Institute, London, UK.

Correspondence: P.J. Barnes, Dept of Thoracic Medicine, Imperial College School of Medicine at the National Heart and Lung Institute, Dovehouse Street, London SW3 6LY, UK.

Fax: 442073515675
\end{abstract}

Keywords: Cystic fibrosis

exhaled nitric oxide

nitrate

nitrite

nitrotyrosine

oxidative stress

Received: August 162000

Accepted after revision February 25 2001

This study was supported by the Hungarian Respiratory Society, Foundation for Patients with Lung \& Heart Diseases (Hungary) and the British Lung Foundation (NHLI, UK).
Nitric oxide (NO) is a gas produced from L-arginine by NO synthases (NOS) [1], of which three isoforms have been identified [2]. NO has an important role in several physiological processes in the respiratory tract, including vascular regulation, neurotransmission, host defense, and cytotoxicity [3, 4]. In inflammatory lung diseases such as asthma and bronchiectasis, NO production is increased, probably due to the induction of inducible NOS (iNOS) [5-6].

Cystic fibrosis (CF) is characterized by recurrent pulmonary infections and increased oxidative stress leading to damage of airways. However, despite chronic airway inflammation in $\mathrm{CF}$, the fractional concentration of exhaled $\mathrm{NO}(F$ eno $)$ is decreased in stable $\mathrm{CF}$ patients $[7,8]$. There are several possible explanations for the paradoxical reduction in $F$ eno, such as reduced expression of iNOS in $\mathrm{CF}$ [9], and an increased metabolism of $\mathrm{NO}$ to reactive nitrogen intermediates, such as nitrite $\left(\mathrm{NO}_{2}^{-}\right)$, nitrate $\left(\mathrm{NO}_{3}{ }^{-}\right)$, s-nitrosothiols and peroxynitrite $\left(\mathrm{ONOO}^{-}\right)$ [8]. The microenvironment of the CF lung - (viscous mucus secretion and increased reactive oxygen species release from inflammatory cells) may facilitate the reaction of $\mathrm{NO}$ with inflammatory oxidants causing an increased formation of reactive $\mathrm{NO}$ metabolites.

Nitrotyrosine has been considered to be an indicator of the involvement of reactive nitrogen species [10]. In the airway epithelium and inflammatory cells of patients with asthma there is a strong immunoreactivity for nitrotyrosine, suggesting a pathophysiological role for reactive nitrogen species in inflammatory lung diseases [11]. Nitration of proteins is a biological process derived from the biochemical interaction of $\mathrm{NO}$ or NO-derived secondary products with reactive oxygen species. Multiple pathways under different conditions can mediate tyrosine nitration although not all nitrating pathways are relevant in vivo [12]. Peroxynitrite can nitrate the tyrosine residues of proteins to yield the stable product 3-nitrotyrosine. In chronic inflammation, or other inflammatory cell-mediated processes, a myeloperoxidase (MPO)-dependent pathways also contribute to the formation of tyrosine nitration, since MPO from polymorphonuclearneutrophils converts 
nitrite into $\mathrm{NO}_{2} \mathrm{Cl}$ and $\mathrm{NO}_{2}$, resulting in tyrosine nitration $[10,12]$.

$\mathrm{NO}$ metabolites, such as $\mathrm{NO}_{2}^{-}$, and $\mathrm{NO}_{3}{ }^{-}$, can be detected in the epithelial lining fluid of the normal human respiratory tract as well as in exhaled breath condensate [8], and probably reflects the NO metabolism in CF more than Feno [8].

This study assessed the levels of 3-nitrotyrosine, $\mathrm{NO}_{2}^{-}$and $\mathrm{NO}_{3}^{-}$in exhaled breath condensate, and $F$ eno and lung function were assessed in clinically stable CF patients, compared with normal subjects. The aim of this study was to explore a noninvasive technique for measurement of oxidative stress in the lungs of patients with $\mathrm{CF}$.

\section{Materials and methods}

\section{Patients}

Patients were recruited from the adult CF clinic at the Royal Brompton Hospital, London UK. Those colonized with Burkholderia cepacia, methicillin resistant Staphylococcus aureus, or with an acute chest infection or disease exacerbation were excluded from the study. The criteria of clinical stability were: no increased cough and/or increased sputum production, no change in quality of sputum (more, purulent, increased "thickness", or presence of blood), no sensation of increased dyspnoea, no decreased exercise tolerance or worsening of forced expiratory volume in one second FEV1. Thirty-six patients with CF (23 male, aged $29 \pm 1 \mathrm{yr}$, FEV1 $59.7 \pm 26.4 \%$ predicted, (range of FEV1 \% pred is 110.4), 16 of whom were receiving inhaled and/or oral corticosteroids, were studied. All patients were life-long nonsmokers. For all patients sputum culture and blood test were performed. Twenty-two $(61 \%)$ were positive for Pseudomonas aeruginosa $\left(>10^{5} \mathrm{cfu} \cdot \mathrm{mL}^{-1}\right)$. Twelve $(33 \%)$ had other pathogens (S. aureus, Haemophilus influenzae) and two sputum cultures had normal flora. Five $(14 \%)$ sputum cultures were positive for both $P$. aeruginosa and $S$. aureus. Circulating leucocyte count (WBC) was $10.5 \pm 0.5 \mathrm{~g} \cdot \mathrm{L}^{-1}$, and sedimentation was $18.3 \pm 3.5 \mathrm{~mm} \cdot \mathrm{h}^{-1}$. The control group consisted of 14 nonsmoking healthy volunteers (six male, $34 \pm 2$ yrs,
FEV1 $101.8 \pm 2.6 \%$ pred). None of the controls had a history of respiratory or cardiovascular disease, or were receiving any medication. The ages of the groups were not statistically different. Clinical characteristics of the subjects are displayed in table 1 .

The study protocol was approved by the Ethics Committee of the Royal Brompton Hospital, and informed consent was obtained from each subject.

\section{Pulmonary function}

Forced vital capacity (FVC) and FEV1 were measured with a dry spirometer (Vitalograph, Buckingham, UK) and the best value of three manoeuvres was expressed as a percentage of the predicted value. Measurement of total lung capacity (TLC) and residual volume (RV) was performed by body plethysmography. (Transfer Factor Model B; PK Morgan; Rainham, UK).

\section{Exhaled nitric oxide measurement}

Feno was measured by chemiluminescence analyser (Model LR2000, Logan Research Ltd, Rochester, UK); sensitivity to NO from $1-500$ parts per billion (ppb) by volume, and with resolution of $0.3 \mathrm{ppb}$. The analyser was designed for online recording of $F$ eno concentrations. It was calibrated with certified NO mixtures (55 ppb) in nitrogen (BOC Special gases, Guilford, UK). Measurement of $F$ eno was made by slow exhalation $\left(5-6 \mathrm{~L} \cdot \mathrm{min}^{-1}\right)$ from TLC for $20-25 \mathrm{~s}$ against a resistance $(3 \pm 0.4 \mathrm{mmHg})$, to prevent nasal contamination. The mean values were taken from the point corresponding to the plateau of end-exhaled $\mathrm{CO}_{2}$ reading, representing the lower respiratory tract sample.

\section{Exhaled breath condensate}

Exhaled breath condensate was collected using a condenser, which allowed the noninvasive collection of nongaseous components of the expiratory air (EcoScreen, Jaeger, Würzburg, Germany). After rinsing their mouths, subjects breathed through a

Table 1.-Patient characteristics

\begin{tabular}{lccc}
\hline & CF not steroid-treated & CF steroid-treated & Normal Subjects \\
\hline Subject n & 20 & 16 & 14 \\
Age yrs & $27 \pm 2$ & $30 \pm 2$ & $34 \pm 2$ \\
Sex M/F & $14 / 6$ & $9 / 7$ & $6 / 8$ \\
FVC \% pred & $86.3 \pm 4.9$ & $74.7 \pm 5.5$ & $100.5 \pm 3.1$ \\
FEV \% pred & $67.5 \pm 6.5$ & $51.9 \pm 4.9$ & $101.8 \pm 2.6$ \\
P. aeruginosa in sputum culture $>10^{5} \mathrm{cfu} \cdot \mathrm{mL}^{-1}$ & 9 & 13 & 0 \\
Therapy: & 0 & 9 & 0 \\
$\quad$ Inhaled steroids & 0 & 5 & 0 \\
Oral steroids & 0 & 2 & 0 \\
Oral+inhaled steroids & 0 & \\
\hline
\end{tabular}

Data are presented as mean \pm SEM or numbers of objects. CF: cystic fibrosis patients; M: male; F: female; FEV1: forced expiratory volume in one second; FVC: forced vital capacity; PA: Pseudomonas aeruginosa. 
mouthpiece and a two-way nonrebreathing valve, which also served as a saliva trap. They were asked to breathe at a normal frequency and tidal volume, wearing a noseclip, for a period of $10 \mathrm{~min}$. The condensate, at least $1 \mathrm{~mL}$, was collected as ice at $-20{ }^{\circ} \mathrm{C}$ and stored at $-70{ }^{\circ} \mathrm{C}$ immediately.

\section{Nitrite and nitrite plus nitrate measurement}

Quantification of $\mathrm{NO}_{2}^{-}$was assessed by a fluorometric assay based upon the reaction of $\mathrm{NO}_{2}^{-}$with 2 , 3-diaminonaphthalene (DAN) to form the fluorescent product, 1-(H)-naphthotriazole [13]. The lower limit of detection for this assay was $0.1 \mu \mathrm{M}$. Briefly, a 100$\mu \mathrm{L}$ sample (exhaled breath condensate) was mixed with $10 \mu \mathrm{L}$ of $0.05 \mathrm{mg} \cdot \mathrm{mL}$ DAN reagent in $0.625 \mathrm{M}$ $\mathrm{HCl}$. The reaction was allowed to proceed at room temperature in the dark and was terminated with $10 \mu \mathrm{L}$ of $1.4 \mathrm{M} \mathrm{NaOH}$. The intensity of the fluorescent signal produced by the product was immediately measured by a fluorometer (Excitatory wavelength: $360 \mathrm{~nm}$, Emmission wavelength: $460 \mathrm{~nm}$ : Biolite F1, Labtech, International Ltd, Uckfield, UK). Incubation of samples with $\mathrm{NO}_{2}^{-}$reductase, allowed the $\mathrm{NO}_{3}{ }^{-}$present in the sample to be measured by this assay after being converted to $\mathrm{NO}_{2}^{-}$.

\section{Nitrotyrosine assay}

Nitrotyrosine was measured with a specific enzyme immunoassay (EIA) (Cayman Chemical, Ann Arbor, MI, USA). The assay has been validated to obtain a high correlation (0.95) between added known amounts of nitrotyrosine and the concentration measured by EIA. The kit has been used to measure nitrotyrosine concentrations in breath condensate. The lower limit of detection for this assay was $3.9 \mathrm{ng} \cdot \mathrm{mL}^{-1}$. The samples were concentrated threefold by a 12-h dryfreeze procedure (Modulyo, Edwards, Crawley, UK) and nitrotyrosine was assessed by the EIA method. The actual concentration of nitrotyrosine was calculated back according to the concentration procedure.

The possible influence of the ventilation rate on nitrotyrosine concentrations in breath condensate was assessed. Normal volunteers breathed at 14 and 28 breaths $\cdot \mathrm{min}^{-1}$ for $15 \mathrm{~min}$, maintaining the same tidal volume. There was no difference in the levels of nitrotyrosine in the two samples collected from the same subject at the different ventilation rates $\left(6.4 \mathrm{ng} \cdot \mathrm{mL}^{-1}\right.$ and $\left.7.1 \mathrm{ng} \cdot \mathrm{mL}^{-1} \mathrm{n}=6\right)$.

To assess the repeatability of the test procedure, 21 samples from seven subjects (triplicates) were measured (variation coefficient of intraassay was $5 \%$ ), samples collected in three consecutive days from the same seven subjects were also measured (day to day repeatability) and the coefficient of variation was $6 \%$. Amylase was undetectable in six samples tested, ruling out saliva contamination of breath condensate by a photometrical method (BM/Hitachi 917, Japan).

\section{Statistical analysis}

Data were expressed as means \pm SEM. Statistical comparisons between groups were performed using a t-test. The correlation between $F$ eno and nitrotyrosine level, as well as nitrotyrosine level and lung function (FVC, FEV1, RV, TLC) was determined by Pearson correlation coefficient and multiple correlation analysis. Discriminant function analysis was performed to compare the steroid and nonsteroid treated groups. Significance was defined as when $\mathrm{p}<0.05$.

\section{Results}

\section{Exhaled nitric oxide}

Feno levels significantly decreased in $\mathrm{CF}$ patients compared to normal subjects $(4.4 \pm 0.3$ versus $5.6 \pm 0.4 \mathrm{ppb}, \mathrm{p}<0.05)$ There was no significant difference between steroid-naive and steroid-treated groups $(4.7 \pm 0.4$ versus $4.1 \pm 0.6 \mathrm{ppb})$ (fig. 1$)$. There was no correlation between $F$ eno and lung function parameters (FVC, FEV1, RV/TLC) of CF patients or between white blood cell (WBC), sedimentation and $F$ eno.

\section{Nitrotyrosine in exhaled breath condensate}

Nitrotyrosine concentrations were detectable in breath condensate of normal subjects $(6.3 \pm$ $\left.0.8 \mathrm{ng} \cdot \mathrm{mL}^{-1}\right)$ and were increased significantly in clinically stable CF patients $\left(25.3 \pm 1.5 \mathrm{ng} \cdot \mathrm{mL}^{-1}, \mathrm{p}<0.0001\right)$ (fig. 2). There was no significant difference in nitrotyrosine levels between the steroid-naive and steroidtreated groups $\left(25.5 \pm 1.9\right.$ versus $\left.24.2 \pm 2.5 \mathrm{ng} \cdot \mathrm{ml}^{-1}\right)$. There was no significant correlation between $F$ eno and nitrotyrosine levels in CF patients. To assess whether the severity of lung disorders in $\mathrm{CF}$ influenced

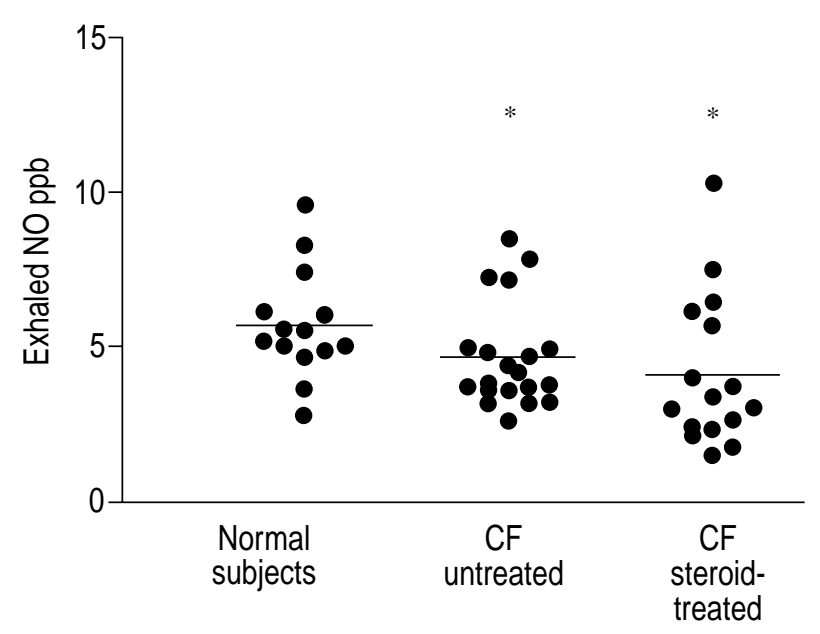

Fig. 1. - Nitric oxide (NO) in exhaled air of normal subjects and patients with cystic fibrosis (CF) who were and were not treated with inhaled/oral steroids. Median levels (horizontal bars) in subjects with CF were significantly lower than normal controls, regardless of usage of inhaled steroids $(*: p<0.05)$. No significant difference was found between $\mathrm{CF}$ groups. ppb: parts per billion. 


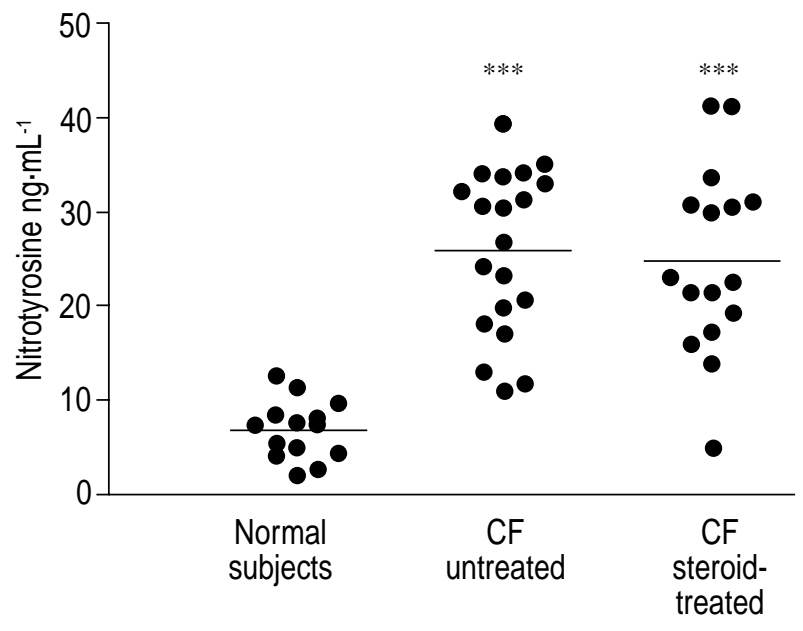

Fig. 2. - Nitrotyrosine in exhaled breath condensate of normal subjects and patients with cystic fibrosis (CF) who were and were not treated with inhaled oral steroids. Median levels (horizontal bars) in subjects with CF were significantly higher than normal controls regardless of usage of inhaled steroids $(* * *: \mathrm{p}<0.001)$.

nitrotyrosine concentrations, the relationship between nitrotyrosine in exhaled breath condensate and pulmonary function in $\mathrm{CF}$ patients was investigated. A positive correlation was observed between nitrotyrosine and FVC $\%$ pred $(\mathrm{r}=0.71, \mathrm{p}<0.0001$, linear regression analysis), FEV1 \% pred $(r=0.70, p<0.0001)$. $\mathrm{RV} / \mathrm{TLC} \%$ pred correlated inversely to the nitrotyrosine level $(\mathrm{r}=-0.70, \mathrm{p}<0.0001)$ indicating that, better lung function was associated with higher nitrotyrosine concentrations (fig. 3). The multiple regression coefficient $(R=0.73)$ was significant $(\mathrm{p}<0.0001)$. There was no significant difference in nitrotyrosine levels between $\mathrm{CF}$ patients with a positive $P$. aeruginosa sputum culture compared to $\mathrm{CF}$ patients infected with other pathogens $\left(25.4 \pm 1.8\right.$ versus $\left.23.8 \pm 2.7 \mathrm{ng} \cdot \mathrm{mL}^{-1}\right)$. The mean difference was not statistically significant. WBC, sedimentation, and neutrophil per cent of WBC were assessed. As multiple regression analysis proved, there was no correlation between these parameters and nitrotyrosine level.

\section{Nitrite and nitrite plus nitrate in breath condensate}

No significant difference was observed in the levels of $\mathrm{NO}_{2}^{-}$and $\mathrm{NO}_{2}^{-}$plus $\mathrm{NO}_{3}^{-}$in exhaled breath condensate between patients with $\mathrm{CF}$ and healthy subjects $(3.9 \pm 0.7$ versus $3.2 \pm 0.5 \mu \mathrm{M} ; 25.4 \pm 6.1$ versus $21.9 \pm 3.2 \mu \mathrm{M})$. There was no correlation between $\mathrm{NO}_{2}^{-}, \mathrm{NO}_{2}^{-}$plus $\mathrm{NO}_{3}^{-}$and nitrotyrosine levels in exhaled breath condensate. Analysing the multiple regression relationship between $\mathrm{NO}_{2}^{-}$and lung function as well as $\mathrm{NO}_{2}^{-}$plus $\mathrm{NO}_{3}^{-}$and lung function (FEV1 \% pred, FVC \% pred, RV/TLC \% pred) no significant association was found.

\section{Discussion}

This study investigated whether nitrotyrosine in exhaled breath condensate was a marker of airway
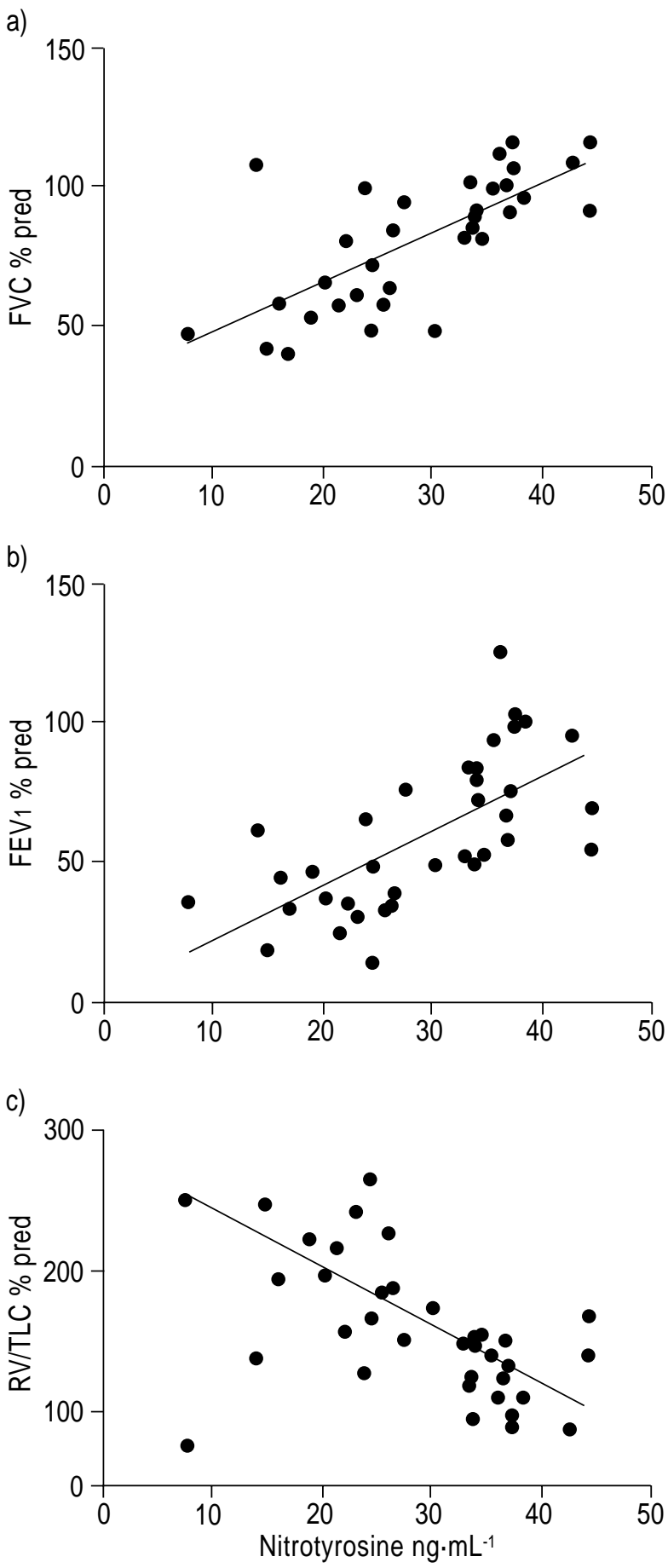

Fig. 3. - Correlations (Pearson) between percentage predicted a) forced vital capacity ( $F V C ; r=0.71, p<0.0001)$; b) forced expiratory volume in one second $\left(\mathrm{FEV}_{1} ; \mathrm{r}=0.70, \mathrm{p}<0.0001\right)$; $\left.\mathrm{c}\right)$ residual volume/total lung capacity (RV/TLC; $r=-0.70, p<0.0001)$ and nitrotyrosine in exhaled breath condensate, of all cystic fibrosis patients measured on the same day.

inflammation in patients with $\mathrm{CF}$. The findings demonstrate that nitrotyrosine in exhaled breath is significantly higher in stable $\mathrm{CF}$ than in nonsmoking healthy controls.

Nitrotyrosine is a marker of protein nitration and can be detected by using a specific nitrotyrosine 
antibody. Nitration of proteins is a biological process derived from the biochemical interaction of $\mathrm{NO}$ or NO-derived secondary products with reactive oxygen species $[12,14]$. Tyrosine nitration can be mediated by multiple pathways under different conditions, suggesting that nitrotyrosine may be considered as a collective indicator for the involvement of reactive nitrogen species [10]. Overall, several nitrating agents can satisfy the requirements for biological nitration, although presently, limited information is available regarding the relative effectiveness of the nitrating species to nitrate tyrosine residues in vivo [12]. Nitration of tyrosine could impact deleteriously on cellular function and viability because this specific modification is known to alter protein function in vitro [10].

Peroxynitrite is a potent oxidant, formed by the rapid reaction of the free radicals $\mathrm{NO}$ and $\mathrm{O}_{2}{ }^{-}$and causes tyrosine nitration in lung tissue $[12,15]$. It can initiate lipid peroxidation in biological membranes, hydroxylation and nitration of aromatic amino acid residues and sulphydril oxidation of proteins $[2-4,12$, $16-17]$. It can be converted to peroxynitrous acid $(\mathrm{ONOOH})$ with subsequent cleavage and release of an intermediate with hydroxyl radical $(\cdot \mathrm{OH})$-like activity [15]. The toxicity of peroxynitrite is due to the direct reactions of the anion $\left(\mathrm{ONOO}^{-}\right)$, as well as reactivities of the acid $(\mathrm{ONOOH})$. Peroxynitrite induces hyperresponsiveness in the airways of guinea pigs [18], inhibits pulmonary surfactant [19], damages pulmonary epithelial cells [16], and oxidizes glutathione [17]. Increased production of peroxynitrite has been reported in the airways and lung parenchyma in several lung diseases, associated with chronic inflammation and/or oxidative stress [20-21]. Activation of inflammatory cells, such as neutrophils, eosinophils and macrophages induce a marked production of $\mathrm{O}_{2}{ }^{-}$ facilitating the formation of peroxynitrite [22].

In chronic inflammation, or other inflammatory cell-mediated process, the myeloperoxidase (MPO)dependent pathways must be considered. Large numbers of polymorphonuclear neutrophils (PMN) accumulate in airways of $\mathrm{CF}$ patients, and lead to increased MPO activity [23]. Activated human PMNs can convert $\mathrm{NO}_{2}{ }^{-}$into inflammatory oxidants through the MPO pathway [10]. It has been suggested that MPO-catalysed nitration in the presence of hydrogen peroxide $\left(\mathrm{H}_{2} \mathrm{O}_{2}\right)$ to form nitrating intermediates from $\mathrm{NO}_{2}^{-}$, a main end-product of $\mathrm{NO}$, is an alternative mechanism of protein nitration, which is independent of peroxynitrite [10].

The other pathways of the formation of nitrotyrosine which are detected in vitro, including direct oxidation of $\mathrm{NO}_{2}^{-}$by hydrogen peroxide or hypochlorous acid or reaction of $\mathrm{NO}$ or nitrogen dioxide $\left(\mathrm{NO}_{2}\right)$ with tyrosyl radicals in vivo have not been completely elucidated [12]. Recent data reveals some clinical conditions result in endogenous airway acidification, which can modulate NO biochemistry [24]. $\mathrm{pH}$ can play a role in the formation of nitrotyrosine, but further studies are necessary to clarify this point in vivo.

Recent publication has demonstrated an increased level of $\mathrm{NO}_{3}^{-}$and nitrotyrosine as well as myeloperoxidase, but not $\mathrm{NO}_{2}^{-}$in $\mathrm{CF}$ sputa suggesting increased production of NO in the lower respiratory tract of CF patients [25]. Cunningham et al. [26] reported an elevated $\mathrm{NO}_{2}^{-}$level in exhaled breath condensate in $\mathrm{CF}$ patients supposing that $\mathrm{NO}_{2}{ }^{-}$is the result of $\mathrm{NO}$ degradation within $\mathrm{CF}$ mucus. Another study has found no elevated levels of $\mathrm{NO}_{2}^{-}$and $\mathrm{NO}_{3}^{-}$ but increased level of myeloperoxidase in $\mathrm{CF}$ sputa [27].

In agreement with the latest study [27] no significant difference was observed in $\mathrm{NO}_{2}{ }^{-}$or $\mathrm{NO}_{2}{ }^{-}$plus $\mathrm{NO}_{3}{ }^{-}$ levels in breath condensate between $\mathrm{CF}$ and normal subjects. The increased level of nitrotyrosine in exhaled breath condensate has overlapped with the elevated level of nitrotyrosine in CF sputa (26). This may indicate that most nitrotyrosine formation is through MPO via increased neutrophil infiltration. This study provided evidence that oxidative stress induced by inflammation produces nitrotyrosine, which presumably reflects increased direct nitration by granulocyte peroxidases.

There was a significant reduction in $F$ eno in patients with CF compared with normal subjects, as previously reported [7, 8, 28]. It has been explained that a significant proportion of NO from the lower airways may have been metabolized by oxidation to biologically active nitrogen oxides before reaching the air spaces [7, 8]. The finding of a marked increase in nitrotyrosine suggests it is possible that NO metabolites in the $\mathrm{CF}$ airways may be metabolized to peroxynitrite. However, no increase was detected in $\mathrm{NO}_{2}^{-}$plus $\mathrm{NO}_{3}^{-}$which may be expected if peroxynitrite is increased suggesting the priority of another pathway (MPO-pathway) of nitrotyrosine formation in $\mathrm{CF}$ airways. There was no significant difference in $F$ eno between $\mathrm{CF}$ patients colonized with only $P$. aeruginosa compared to those colonized with other species, in agreement with a recent publication by Thomas et al. [28].

In this study no significant difference was found in the $F$ eno or nitrotyrosine in breath condensate between patients treated or not treated with steroids. Steroid therapy is the mainstay of treatment in asthma [5, 29], but remains controversial in $\mathrm{CF}$ [30]. Nitrotyrosine formation in the airways, which is not influenced by steroid treatment in $\mathrm{CF}$ patients, may reflect a different type of inflammation that is not steroid sensitive, in the same way that the inflammation of chronic obstructive lung disease (COPD) fails to be suppressed by steroid therapy [31].

A strong inverse correlation was demonstrated between the level of nitrotyrosine and the severity of the lung disease measured by lung function. There are conflicting data regarding the correlation of $\mathrm{NO}$ oxidative metabolites and lung function in CF. GRASEMANN et al. [7] found a positive correlation between $F$ eno concentration and FVC, but not FEV1, indicating that FENO is inversely related to disease severity [7] and also reported that NO metabolites in sputum correlated positively with FEV1 as well as FVC [32]. In contrast, Ho et al. [8] found no correlation between $\mathrm{NO}_{2}^{-}$in exhaled breath condensate and lung function. The positive correlation between nitrotyrosine in exhaled breath and the lung function parameters suggests that higher nitrotyrosine 
levels reflect higher NO production in airways of CF patients with milder disease. Probably, like $F$ eno in patients with advanced disease, the damage of lung parenchyma may contribute to the decreased NO production. Although no correlation could be detected between nitrotyrosine levels in breath condensate and $F$ eno and $\mathrm{NO}$ metabolites $\left(\mathrm{NO}_{2}{ }^{-}, \mathrm{NO}_{2}{ }^{-}\right.$ plus $\mathrm{NO}_{3}^{-}$) which suggests the possibility of nitrotyrosine formation rather through the MPO pathway. The other possible explanation is that the impaired ventilation in small bronchi due to increased amount of bronchial secretion, destruction of airway wall and increased anatomical dead space [33], in advanced disease, may inhibit the release of free nitrotyrosine from the lower airways into exhaled air. Yet another explanation might be the differences in the lung clearance of nitrotyrosine. In the presence of severe ventilation inhomogenities, the clearance of nitrotyrosine might be altered. Furthermore, $\mathrm{pH}$ may play a role in the formation of nitrotyrosine. If more severe disease were associated with a more acidic $\mathrm{pH}$, peroxynitrite would be more likely to dissociate into hydroxyl and nitrogen dioxide and less likely to react with tyrosine radicals yielding the stable 3-nitrotyrosine.

On the other hand, several studies have suggested that NO might act as an antioxidant to counteract the cytotoxic effects of reactive species [34]. Supposing that increased nitrotyrosine levels are associated with milder disease reflecting higher NO production, it may protect the lung against injury by the reactive oxidant radicals.

In summary, this study provided evidence for increased production of nitrotyrosine in patients with $\mathrm{CF}$, which may reflect increased formation of reactive nitrogen species such as peroxynitrite or direct nitration by granulocyte peroxidases. Nitrotyrosine, which is formed in the airways and can be collected in the exhaled breath condensate, may be a marker of oxidative stress in $\mathrm{CF}$ patients. Further studies are necessary to clarify the complex chemistry of $\mathrm{NO}$ and its oxidative products, such as peroxynitrite in chronic suppurative lung diseases.

The elevation in nitrotyrosine may reflect increased formation of reactive nitrogen species such as peroxynitrite or direct nitration by granulocyte peroxidases, indicating increased oxidative stress in airways of cystic fibrosis patients.

\section{References}

1. Barnes PJ, Belsivi MG. Nitric oxide and lung disease. Thorax 1993; 48: $1034-1043$.

2. Gaston B, Drazen JM, Loscalzo J, Stamler JS. The biology of nitrogen oxides in the airways. Am J Respir Crit Care Med 1994; 149: 538-551.

3. Moncada S, Palmer MJ, Higgs EA. Nitric oxide: physiology, pathology, pathophysiology, and pharmacology. Pharmacol Rev 1991; 43: 109-142.

4. Beckman JS, Koppenol WH. Nitric oxide, superoxide, and peroxynitrite: the good, the bad, and the ugly. $\mathrm{Am}$ J Physiol 1996; 271: C1424-C1437.

5. Kharitonov SA, Yates D, Robbins RA, LoganSinclair, Shinebourne E, Barnes PJ. Increased nitric oxide in exhaled air of asthmatic patients. Lancet 1994; 343: $133-135$.

6. Kharitonov SA, Wells AU, O'Connor BJ, Hansell DM, Cole PJ, Barnes PJ. Elevated levels of exhaled nitric oxide in bronchiectasis. Am J Respir Crit Care Med 1995; 151: 1889-1893.

7. Grasemann H, Michler E, Wallot M, Ratjen F. Decreased concentrations of exhaled nitric oxide (NO) in patients with cystic fibrosis. Pediatr Pulmonol 1997; 24: $173-177$.

8. Ho LP, Innes JA, Greening AP. Nitrite levels in breath condensate of patients with cystic fibrosis is elevated in contrast to exhaled nitric oxide. Thorax 1998; 53: $680-684$.

9. Kelley TJ, Drumm ML. Inducible nitric oxide synthase expression is reduced in cystic fibrosis murine and human airway epithelial cells. $J$ Clin Invest 1998; 102: $1200-1207$.

10. Eiserich JP, Hristova M, Cross CE, et al. Formation of nitric oxide-derived inflammatory oxidants by myeloperoxidase in neutrophils. Nature 1998; 391: $393-397$.

11. Kaminsky DA, Mitchell J, Carroll N, James A, Soultanakis R, Janssen Y. Nitrotyrosine formation in the airways and lung parenchyma of patients with asthma. J Allergy Clin Immunol 1999; 104: 747 754.

12. Ischiroppoulos H. Biological Tyrosine Nitration: A Pathophysiological Function of Nitric Oxide and Reactive Oxygen Species. Arch of Biochem and Biophys 1998; 356: 1-11.

13. Marzinzig M, Nussler AK, Stadler J, et al. Improved methods to measure end products of nitric oxide in biological fluids: nitrite, nitrate, and s-nitrosothiols. Biology and Chemistry 1997; 2: 177-189.

14. Van der Vliet A, Eiserich JP, Shigenaga MK, Cross CE. Reactive nitrogen species and tyrosine nitration in the respiratory tract. Am J Respir Crit Care Med 1999; 160: $1-9$.

15. Beckman JS. Oxidative damage and tyrosine nitration from peroxynitrite. Chem Res Toxicol 1996; 9: 836844.

16. Matalon $\mathrm{S}, \mathrm{Hu} \mathrm{P}$, Ischiropoulos $\mathrm{H}$, Beckman JS. Peroxynitrite inhibition of oxygen consumption and ion transport in alveolar type II pneumocytes. Chest 1994; 105: 74S.

17. Radi RJ, Beckman JS, Bush KM, Freeman BA. Peroxyntrite oxidation of sulfhydrils. J Biol Chem 1991; 226: $4244-4250$.

18. Sadeghi-Hashjin G, Folkerts G, Henricks PAJ, et al. Peroxynitrite induces airway hyperresponsiveness in guinea pigs in vitro and in vivo. Am J Respir Crit Care Med 1996; 153: 1697-1701.

19. Haddad IY, Ischiropoulos H, Holm BA, Beckman JS, Baker JR, Matalon S. Mechanism of peroxynitrite induced injury to pulmonary surfactants. Am J Physiol 1993; 265: L555 - L564.

20. Wizeman T, Gardner C, Laskin J, et al. Production of nitric oxide and peroxynitrite in the lung during acute endoxemia. J Leukoc Biol 1994; 56: 759-768.

21. Ischiropoulus $\mathrm{H}$, al-Mehdi $\mathrm{AB}$, Fisher $\mathrm{AB}$. Reactive species in ischemic rat lung injury: contribution of peroxynitrite. Am J Physiol 1995; 269: L158L164.

22. Babior BM. The respiratory burst of phagocytes. J Clin Invest 1984; 73: 599-601.

23. Witko-Sarsat V, Allen RC, Paulais M, et al. Disturbed 
myeloperoxidase-dependent activity of neutrophils in cystic fibrosis homozygotes and heterozygotes, and its correction by amiloride. J Immunol 1996; 15: 157: $2728-2735$.

24. Hunt JF, Fang K, Malik R, et al. Endogenous airway acidification. Am J Respir Crit Care Med 2000; 161: 694-699.

25. Jones KL, Hegab AH, Hiffman BC, et al. Elevation of nitrotyrosine and nitrate concentration in cystic fibrosis sputum. Pediatr Pulmonol 2000; 30: 79 85.

26. Cunningham S, McColm JR, Ho LP, Greening AP, Marshall TG. Measurement of inflammatory markers in the breath condensate of children with cystic fibrosis. Eur Respir J 2000; 15: 955-957.

27. Van Der Vliet A, Nguyen MN, Shigenaga MK, Eiserich JP, Marelich GP, Cross CE. Myeloperoxidase and protein oxidation in cystic fibrosis. Am J Physiol Lung Cell Mol Physiol 2000; 279: L537-L546.

28. Thomas SR, Kharitonov SA, Scott SF, Hodson ME, Barnes PJ. Nasal and exhaled nitric oxide is reduced in adult patients with cystic fibrosis and does not correlate with cystic fibrosis genotype. Chest 2000; 117: $1085-1089$.

29. Barnes PJ. Antiinflammatory therapy in asthma. Annu Rev Med 1993; 44: 229-249.

30. Conway SP, Watson A. Nebulised bronchodilators, corticosteroids, and rhDNase in adult patients with cystic fibrosis. Thorax 1997; 52: Suppl. 2: S64-S68.

31. Keatings VM, Jatakanon A, Worsdell YM, Barnes PJ. Effects of inhaled and oral glucocorticoids on inflammatory indices in asthma and COPD. Am J Respir Crit Care Med 1997; 155: 542-548.

32. Grasemann H, Ioannidis I, Tomkiewicz RP, de Groot H, Rubin BK, Ratjen F. Nitric oxide metabolites in cystic fibrosis lung disease. Arch Dis Child 1998; 78 : $49-53$.

33. Hirsch JA, Zhang SP, Rudnick MP. Resting oxygen consumption and ventilation in cystic fibrosis. Pediatr Pulmonol 1989; 6: 19-26.

34. Wink DA, Hanbauer I, Krishna MC, et al. Nitric oxide protects against cellular damage and cytotoxicity from reactive oxygen species. Procl Natl Acad Sci USA 1993; 90: 9813-9817. 